\title{
Beyond the mega-trial: certainty and uncertainty
}

\author{
J R Hampton, A M Skene
}

In the accompanying viewpoint (page 348) Topol and Califf describe and justify one of the largest clinical trials so far attempted; in GUSTO (Global Utilisation of Streptokinase and Tissue plasminogen activator (alteplase) for Occluded coronary arteries) some 40000 patients will be recruited to compare the effects of streptokinase (SK), alteplase (rt-PA), and their combination with two different heparin regimes. Although opinions may vary as to the likely outcome of GUSTO, many will agree with the song from Oklahoma, that "things have gone as far as they can go": it is hard to envisage any rationale that would lead to a further order-of-magnitude increase in trial size. Furthermore, as trials of this size are so expensive and consume so much research activity in so many centres, there must be a practical limit to the number of very big trials that can be mounted at any one time in any particular therapeutic area. GUSTO will undoubtedly provide an answer to its primary objective and be the source of much additional information; but mega-trials are not a panacea for the limitations inherent in smaller studies.

\section{Background}

The randomised controlled clinical trial, double blind when feasible, is perhaps the most powerful tool that has been developed for the furtherance of patient treatment. Though little medical treatment is actually based on trial results, it is generally agreed that this should be the aim. In most instances (though with some notable exceptions) a new treatment is not introduced unless adequate trials have been performed. For 30 years cardiovascular developments have been based on state of the art clinical trials, and trial design and conduct have improved considerably as experience has been gained. The reason for the multiplicity of cardiovascular trials is in part clinical and part commercial: coronary artery disease is common and myocardial infarction is one of the main causes of acute medical admission to hospital, so not only is there a great need for improved treatments but also patients are readily available for inclusion in trials. Furthermore the pharmaceutical industry has no problem in providing finance because the market for its products is large. The increasing use of anticoagulants, $\beta$ blockers, aspirin, and thrombolytics reflects both the progress of cardiovascular therapeutics and the maturation of trial design.

\section{Past trials}

anticoagulants

The trials of indirect anticoagulants, phenindione, and warfarin, in the $1960 \mathrm{~s}^{12}$ were based on the misconception that clotting and thrombosis were the same thing. The trials were small-not even mini-trials according to Topol and Califf's definition. The Medical Research Council trials of 1964 and 1969 contained 383 and 1427 patients. The general principle that a larger sample size will increase the likelihood that a trial will confirm the existence of a small treatment difference is now widely accepted, but the need to examine this relation quantitatively and use this to determine trial size was not at that time understood (at least by clinicans) and by today's standards the results of these trials could never be regarded as more than suggestive. Nevertheless, it was believed that anticoagulants prolonged long-term survival after myocardial infarction, particularly in younger men with repeated infarcts. The anticoagulant story might have been followed up and resolved had the attention of cardiologists not been diverted by a sudden interest in arrhythmias.

\section{BETA BLOCKERS}

Because it was believed that suppressing arrhythmias would improve survival in myocardial infarction, and because $\beta$ blockers had antiarrhythmic properties, a long series of small trials ${ }^{3}$ followed the observation by Snow that propranolol did indeed improve survival. ${ }^{4}$ These early small trials gave results that were at times conflicting and often confusing, and it was only when a trial of reasonable size (1884 patients, but still a mini-trial) was conducted with timolol ${ }^{5}$ that an answer was obtained on which clinicians were prepared to base their practice. This was followed by similarly sized trials, not all of which gave equally convincing results (Beta Blocker Heart Attack Trial (BHAT) 3837 patients, metoprolol trial 1395 patients ${ }^{67}$ ) but nevertheless the place for $\beta$ blockers after myocardial infarction was established. The place of antiarrhythmic therapy as such is still far from established, with a deleterious effect of antiarrhythmic agents having been demonstrated in the Cardiac Arrhythmia Suppression Trial (CAST). ${ }^{8}$

\section{ASPIRIN}

Trials of aspirin followed the same general pattern as those of $\beta$ blockers: the early trials were small (1239 in the Welsh Study, ${ }^{9} 4524$ in the Aspirin Myocardial Infarction Study 
(AMIS), ${ }^{10} 2026$ in the Persantine Aspirin Reinfarction Study (PARIS) ${ }^{11}$ ) and gave conflicting results and it was only with the publication of ISIS-2 (Second International Study of Infarct Survival) in which trial 17187 patients had been allocated to treatment with aspirin or placebo that aspirin became accepted therapy. ${ }^{12}$

\section{THROMBOLYSIS}

With the experience gained in the anticoagulant, $\beta$ blocker, and aspirin trials the way was open for a rapid advance when interest switched to thrombolysis. Here was an "old" treatment not adequately investigated,,$^{13}$ and again the first of modern trials was inconclusive. ${ }^{14}$ Then trials came along which were big in their day and the value of thrombolysis was proven. GISSI-I ${ }^{15}$ (Gruppo Italiano per lo Studio della Streptochinasi nell'Infarto Miocardico) included 11806 patients, ASSET ${ }^{16}$ (Anglo-Scandinavian Study of Early Thrombolysis) 5009 patients, and ISIS-2 $2^{12} 17187$ patients. The techniques and attitudes necessary for the organisation of multicentre international trials were now in place, and trial size as such was clearly not a problem.

\section{Comparison of thrombolytic agents}

The next logical step was to compare thrombolytic agents, even though the similar results obtained when streptokinase and alreplase were compared with placebo suggested that the effects of these agents might be very similar. The initial comparison, GISSI-2 ${ }^{17}$ (12 409 patients), was "too small" to have good power to detect a difference of $1 \%$ in the absolute mortality rates of the two agents (the best that could be expected) and so was enlarged by the addition of an international section, ${ }^{18}$ making a total of 20891 patients. Streptokinase and alteplase gave similar results but the trial was immediately criticised because the use of heparin might not have been optimal. ISIS- $3^{19}$ (38 574 patients) confirmed that streptokinase and alteplase had a similar effect on mortality, and also that anistreplase (APSAC), which in its initial minitrial (1258 patients) had shown the greatest improvement in survival rate compared with placebo, ${ }^{20}$ had an identical effect. Once again, however, doubts were expressed about the optimal use of heparin, and hence the 40000 patient GUSTO Study.

This story of ever-increasing trial size is largely attributable to the willingness of the pharmaceutical industry to fund trials that might be expected to sell its products. The interest of industry has extended to problems such as the place of angioplasty after thrombolysis, ${ }^{21}{ }^{22}$ but without industrial support it has not been possible to answer questions such as whether the effect of $\beta$ blockers and aspirin are additive. The problem remains how to answer such questions with lower funding and smaller patient groups, and various models have been proposed.

\section{Alternative trial options}

FACTORIAL DESIGN

An attractive possibility is that of the factorial design, in which two (or even three) treatments are compared with placebo by independent randomisation within one trial umbrella. This worked well in ISIS-2, which allowed the effect of aspirin to be studied together with streptokinase without the expense of an independent trial. However, these designs are only fully effective when there is no interaction between the two agents, and in the GISSI-2 International Study ${ }^{18}$ it seemed that there was such an interaction between the effect of alteplase and heparin. Multifactorial designs are, in fact, something of a gamble.

\section{META-ANALYSES}

Meta-analyses of many trials, each of them on its own inadequate, is sometimes held out as a substitute for a single adequate trial. However, while meta-analyses can give an overall answer such as "antiplatelet agents reduce fatality in patients with vascular disease", or " $\beta$ blockers reduced fatality after myocardial infarction", they can never tell a clinician which antiplatelet agent or $\beta$ blocker, in what dose, to give to any particular patient. Meta-analysis can provide a theoretical background against which to plan further trials, but not much more.

\section{SUB-SET ANALYSES}

Sub-set analyses within individual trial results have at times been used instead of additional prospective trials to identify patients who are most likely to benefit from a particular treatment, but it is now accepted that such analyses should be used with extreme caution and are more likely to be misleading than helpful.

\section{SURROGATE END POINTS}

This leaves the surrogate end point for the poor man's clinical trial. The strategy is to identify some aspect of the patient's response that is amenable to precise measurement and is also correlated with the end point of interest. As an example, left ventricular dilatation is correlated with one month mortality after myocardial infarction. If a treatment can be shown to reduce left ventricular diltatation, then it is argued that such a treatment will also save lives. The fallacy of such arguments has been shown in the various lipid-lowering trials, all of which failed to demonstrate the fatality reduction that was assumed would go hand in hand with a reduction in plasma cholesterol. ${ }^{23-26}$ Similarly with high blood pressure: the ability of a drug to lower pressure could be taken as a surrogate for mortality reduction, on the assumption that the effects of propranolol and bendrofluazide shown in the MRC trial ${ }^{27}$ (17 345 patients) could be extrapolated to all other hypotensive agents. The PACK (Prevention of Atherosclerotic Complications with Ketanserin) trial in 3899 patients with peripheral vascular disease $^{28}$ put an end to this convenient theory, for this study showed that a drug of proven hypotensive efficacy could under certain circumstances be dangerously arrhythmogenic. 
MEGA-TRIALS

It seems then that there is little alternative to the mega-trial for comparing the efforts of two or more agents, particularly when, as with myocardial infarction, there is little scope for further reductions in mortality. Certainly, when there are theoretical or laboratory based reasons to suppose that a new drug in a particular class would reduce mortality more than an older drug of that type, a comparative trial can be set up if the manufacturer is prepared to pay for it. CAPRIE (Clopodogrel v Aspirin in Patients at Risk of Ischaemic Events) is an example of this: it has been decided to set up, as the first major trial of this new antiplatelet agent, a comparison with aspirin in 15000 patients with coronary, cerebral, or peripheral vascular disease. This is an expensive and commercially high-risk undertaking, but it is probably the only way to find out whether such a drug has a clinical role.

The problem is slightly different when a completely new class of drug appears for the treatment of a condition for which there is already established therapy-for example, the phosphodiesterase inhibitors for the treatment of heart failure. Under these circumstances withholding the established treatment (in the case of heart failure, an angiotensin converting enzyme inhibitor ${ }^{29}{ }^{30}$ ) is unethical and the new therapy has to be added to the old. The chances of achieving a further large reduction in fatality by such an addition are inevitably small, and the risk that the clinical trial programme will fail to show a benefit is high. In a sense the demonstration in the PROMISE (placebo controlled survival study of oral milrinone in severe heart failure) trial that milrinone increased fatality ${ }^{31}$ was useful in eliminating this drug, but suppose its effect had been neutral? Would this have implied that milrinone was of no use? After all it had clearly been shown effective in short-term intravenous studies.

\section{The future}

Clearly there will always be a need for new drugs. Ideally they will be more effective, but in most cases their value will be for individual patients who fail to respond to established therapy, or who are for some reason intolerant of it. If a new drug is only to be licensed if it has been shown in a mega-trial to be superior to its predecessor, then the introduction of compounds must inevitably be inhibited. The cost of the trial itself, taken in context of a likely result, would become an unrealistic financial risk even for the largest pharmaceutical company. For treatments without pharmaceutical backing - for example, comparison of coronary artery bypass grafting and percutaneous transluminal coronary angioplasty such as are being made in the RITA (Randomised Intervention Treatment of Angina) Trial ${ }^{32}$-mega-trials are already an impossibility. We need to change prevailing attitudes to the evaluation of treatments to one that recognises the value of information already collected and appreciates the nature of clinical decision-making. In particular, we need to develop further the concept of equivalence of medical therapies. All too often, the issues of treatment equivalence and the problem of interpreting a negative trial have been confused. When the difference in expected benefit to the patient is of no practical importance, it does not matter if a small treatment difference is missed.

\section{Alternative approaches}

One possible approach involves a reexamination of the place of the uncontrolled study that uses data from another source as the comparator. Arguments against the use of historical controls emphasise the potential sources of bias inherent in this approach. ${ }^{33}$ It may be difficult to ensure that the treatment groups are truly comparable, or that ostensibly similar data-disease history or concurrent therapy, etc-have been recorded in a similar manner. Finally, developments in clinical practice between the collection of the control data and the data pertaining to the new therapy may be important. These concerns are important, but do not automatically rule out the use of historical data especially in those areas where mega-trials are now contemplated. Consider the introduction of a new thrombolytic agent, which may have the potential for fewer side effects or benefit of a reduced cost. Superiority over existing agents is not expected. However, we now know so much about the effect of streptokinease and alteplase in patients with myocardial infarction from the previously completed trials where the patient populations have been clearly identified, that we should perhaps be prepared to set limits in respect of efficacy and safety that the new product should satisfy and allow an open study to determine whether these limits can be satisfied.

Trials to show the equivalence of two therapies are not new. ${ }^{34} 35$ It has been argued that the sample size for such studies should be determined with reference to a confidence interval for the difference in the efficacy of the two therapies. One requires that in the event that the study shows that the two treatments are similar, the confidence interval for the difference should be acceptably "small". Others have argued that in addition sequential methods should be used, with recruitment to a trial stopped when it is clear that that treatment effects are sufficiently close to be judged as equivalent. ${ }^{36}{ }^{37}$ However, there is as yet little agreement on how to define equivalent therapies and cautious definitions lead yet again to large trial sample sizes.

Equivalent therapies are not necessarily identical therapies. The clinician choosing between two alternative therapies is making a decision. $\mathrm{He}$ is conscious of the benefits of a good outcome and of the costs or "losses" of a bad outcome. Decision theory ${ }^{38}$ provides a framework for analysing such decisions, and within this framework equivalent therapies are clearly those where the expected gains or losses associated with one therapy compared with another are not considered to be clinically important. Clinical trials allow one to estimate the probabilities associated with each distinct 
outcome for each treatment. However, in many situations the costs assigned to the various outcomes may be such that the probabilities need be known only imprecisely for equivalence to be accepted. Large trials may not be necessary.

For complete certainty about the relative effect of one drug compared with another there is no alternative to the mega-trial. Where the pharmaceutical industry sees it to be in its commercial interests the mega-trial will doubtless continue. But this may mean that minor improvements in drug development are missed because they are commercially non-viable. We may have to learn to quantify better the costs and benefits of therapies and live with a little uncertainty if we are to progress.

1 Second report of the Working Party on Anticoagulan Therapy in Coronary Thrombosis to the Medical Research Council 1964. An assessment of long-term anticoagulant administration after cardiac infarction. BMJ 1964;ii:837-43.

2 Report of the Working Party on Anticoagulant Therapy in Coronary Thrombosis to the Medical Research Council. Assessment of short-term anticoagulant administration after cardiac infarction. BMJ 1969;ii:335-42.

3 Hampton JR. Should every survivor of a heart attack be given a beta-blocker? $B M J$ 1982;285:33-6.

4 Snow PJD. Effect of propranolol in myocardial infarction Lancet 1965; ii:551-3.

5 The Norwegian Multicentre Study Group 1981. Timololinduced reduction in mortality and reinfarction in patients surviving acute myocardial infarction. $N$ Engl J Med 1981;304:801-7.

6 Hjalmarson A, et al. Effect on mortality of metoprolol in acute myocardial infarction. Lancet $1981 ;$;ii:823-6.

7 Co-operative trial: Preliminary Report. The beta-blocker heart attack trial. JAMA 1981;246:2073-4.

8 The Cardiac Arrhythmia Suppression Trial (CAST) Investigators. Preliminary report: effect of encainide and flecainide on mortality in a randomized trial of arrhythmia suppression after myocardial infarction. $N$ Engl J Med 1989:321:406-12.

9 Elwood PC, Cochrane AL, Burr ML, et al. A randomised controlled trial of acetyl salicylic acid in the secondary prevention of mortality from myocardial infarction. $B M J$ 1974;i:436-40.

10 Aspirin Myocardial Infarction Study Research Group (AMIS). A randomised, controlled trial of aspirin in persons recovered from myocardial infarction. JAMA 1980;243:661-7.

11 The Persantine-Aspirin Reinfarction Study Research Group (PARIS). Persantine and aspirin in coronary heart disease. Circulation 1980;62:449-61.

12 Randomised trial of intravenous streptokinase, oral aspirin, both or neither among 17187 cases of suspected acute myocardial infarction: ISIS-2. Lancet 1988;ii:349-60.

13 European Working Party. Streptokinase in recent myocardial infarction: A controlled multicentre trial. $B M J$ 1971;i:325-31.

14 The ISAM Study Group. A prospective trial of intravenous streptokinase in acute myocardial infarction. $N$ Engl $J$ Med 1986;314:1465-71.

15 GISSI (Gruppo Italiano per lo Studio della Streptochinasi nell'Infarto Miocardico). Lancet 1986;1:397-401.
16 ASSET Study Group. (Anglo-Scandinavian Study of Early Thrombolysis). Trial of tissue plasminogen activator for mortality reduction in acute myocardial infarction. Lancet 1988;ii:525-30.

17 GISSI-2. A factorial randomised trial of alteplase versus streptokinase and heparin versus no heparin among 12490 patients with acute myocardial infarction. Lancet 1990 patients with

18 The International Study Group. In-hospital mortality and clinical course of 20891 patients with suspected acute myocardial infarction randomised between alteplase and streptokinase with or without heparin. Lancet 1990 336:71-5.

19 ISIS-3: a randomised comparison of streptokinase $v s$ tissue plasminogen activator $v s$ anistreplase and of aspirin plus heparin $v s$ aspirin alone in 41299 cases of suspected myocardial infarction. ISIS-3 (Third International Study of Infarct Survival) Collaborative Group. Lancet 1992 339:753-70.

20 AIMS Trial Study Group. Long-term effects of intravenous anistreplase in acute myocardial infarction: final report of anistreplase in acute myocardial infarction:

21 TIMI Research Group. Immediate vs delayed catheterization and angioplasty following thrombolytic therapy for acute myocardial infarction. JAMA 1988;260:2849-58.

22 SWIFT trial of delayed elective intervention vs conservative treatment after thrombolysis with anistreplase in acute myocardial infarction. BMJ 1991;302:555-60.

23 Strategies for the prevention of coronary heart disease: policy statement for the European Atherosclerosis Society. Eur Heart J 1987;8:77-88.

24 Frick MH, Elo O, Haapa K, et al. Helsinki Heart Study: primary-prevention trial with gemfibrozil in middle-aged men with dyslipidemia: safety of treatment, changes i factors, and incidence of coronary heart disease. $N$ Engl J Med 1987;317:1237-45.

25 Committee of Principal Investigators. A cooperative trial in the primary prevention of ischaemic heart disease using the primary prevention of ischaemic heart

26 Lipid Research Clinics Program. The Lipid Research Clinics coronary primary prevention trials results. JAMA 1984;251:351-64

27 Medical Research Council Working Party. MRC trial of treatment of mild hypertension: principal results. $B M$ 1985;291:97-104.

28 Prevention of Atherosclerotic Complications with Ketanserin Trial Group. Prevention of atherosclerotic complications: controlled trial of ketanserin $B M J 1989 ; 298$ : 424-30.

29 The CONSENSUS Trial Study Group. Effects of enalapril on mortality in severe congestive heart failure. Results of the Co-operative North Scandinavian Enalalpril Surival Study (CONSENSUS). N Engl J Med 1987;316:1429-35.

30 Cohn JN, Johnson G, Ziesche S, et al. A comparison of enalapril with hydralazine-isosorbide dinitrate in the enalapril with hydralazine-isosorbide dinitrate in the treatment of chronic

31 PROMISE Study Research Group. Effect of oral milrinone on mortality in severe chronic heart failure. $N$ Engl J Med 1991;325:1468-75.

32 Editorial. BARI, CABRI, EAST, GABI and RITA: Coronary angioplasty on trial. Lancet 1990;335:1315-6.

33 Pocock SJ. Clinical trials: a practical approach. Chichester: J Wiley \& Sons, 1983.

34 Dussleman S, Simon R. Planning and monitoring of equivalence studies. Biometrics 1990;46:329-36.

35 Freedman LS, Spiegelhalter DJ. Application of Bayesian statistics to decision making during a clinical trial. Stat Med 1992;11:23-36.

36 Whitehead J. The design and analysis of sequential clinical trials. Chichester: Horwood, 1983.

37 Gould A, Pecone V. Group sequential methods for clinical trials allowing early acceptance of $\mathrm{H}_{0}$ and incorporating costs. Biometrika 1982;69:75-80.

38 Skene AM. Formal approaches to the analysis of clinica decisions. In: Ingram $\mathrm{D}$, Bloch $\mathrm{R}$, eds. Mathematica methods in medicine. Chichester: J Wiley \& Son, 1984: $119-60$. 